\title{
The current treatment landscape of irritable bowel syndrome in adults in Hong Kong: consensus statements
}

\author{
Justin CY Wu *, Annie 00 Chan, Yawen Chan, Gordon CL Cheung, TK Cheung, Ambrose CP Kwan, \\ Vincent KS Leung, Arthur DP Mak, WC Sze, Raymond Wong
}

\section{A B S T R A C T}

Objective: The estimated prevalence of irritable bowel syndrome in Hong Kong is $6.6 \%$. With the increasing availability of pharmacological and non-pharmacological treatments, the Hong Kong Advisory Council on Irritable Bowel Syndrome has developed a set of consensus statements intended to serve as local recommendations for clinicians about diagnosis and management of irritable bowel syndrome.

Participants: A multidisciplinary group of clinicians constituting the Hong Kong Advisory Council on Irritable Bowel Syndrome-seven gastroenterologists, one clinical psychologist, one psychiatrist, and one nutritionist-convened on 20 April 2017 in Hong Kong.

Evidence: Published primary research articles, metaanalyses, and guidelines and consensus statements issued by different regional and international societies on the diagnosis and management of irritable bowel syndrome were reviewed.

Consensus Process: An outline of consensus statements was drafted prior to the meeting. All consensus statements were finalised by the participants during the meeting, with $100 \%$ consensus.

Conclusions: Twenty-four consensus statements were generated at the meeting. The statements were divided into four parts covering: (1) patient assessment; (2) patient's psychological distress; (3) dietary and alternative approaches to managing irritable bowel syndrome; and (4) evidence to support pharmacological management of irritable bowel syndrome. It is recommended that primary care physicians assume the role of principal care provider for patients with irritable bowel syndrome. The current statements are intended to guide primary care physicians in diagnosing and managing patients with irritable bowel syndrome in Hong Kong

Hong Kong Med J 2017;23:641-7

DOI: $10.12809 / \mathrm{hkmj} 177060$

${ }^{1} \mathrm{JCY} W \mathrm{~W}^{*}, \mathrm{MB}, \mathrm{ChB}, \mathrm{MD}$

${ }^{2} \mathrm{AOO}$ Chan, MB, ChB, PhD

${ }^{3}$ Y Chan, MSocSci

${ }^{4}$ GCL Cheung, MPhil, RD (UK)

${ }^{5}$ TK Cheung, MB, BS, PhD

${ }^{5}$ ACP Kwan, MB, BS

${ }^{6}$ VKS Leung, MB, BS

${ }^{7}$ ADP Mak, MB, BS, MRCPsych

${ }^{5}$ WC Sze, MB, BS, GradDFM

${ }^{5} \mathrm{R}$ Wong, $M D, P h D$

${ }^{1}$ Department of Medicine and Therapeutics, The Chinese University of Hong Kong, Shatin, Hong Kong

2 Department of Gastroenterology and Hepatology, Hong Kong

Sanatorium \& Hospital, Happy Valley, Hong Kong

${ }^{3}$ Hong Kong Institute of Integrative Medicine, The Chinese University of Hong Kong, Shatin, Hong Kong

${ }^{4}$ Hong Kong Nutrition Association, Hong Kong

${ }^{5}$ Private specialist in Gastroenterology and Hepatology, Hong Kong

${ }^{6}$ Department of Gastroenterology and Hepatology, Hong Kong Baptist Hospital, Kowloon Tong, Hong Kong

${ }^{7}$ Department of Psychiatry, The Chinese University of Hong Kong, Shatin, Hong Kong

* Corresponding author: justinwu@cuhk.edu.hk

\section{Introduction}

Irritable bowel syndrome (IBS) is a common condition encountered by primary care physicians, with an estimated local prevalence of $6.6 \%,{ }^{1}$ yet it remains poorly understood. Irritable bowel syndrome is believed to be a multifactorial disease involving motility dysfunction, visceral hypersensitivity, psychiatric co-morbidity, neuroendocrine dysfunction, genetics and epigenetics, dysbiosis, diet, and immune activation. ${ }^{2}$

First-line pharmacological treatment for IBS may include smooth muscle relaxants, antidiarrhoeal drugs, or laxatives. Nonetheless significant recent advances have been made in the understanding of IBS and new treatment modalities have emerged, such as dietary modifications and the use of probiotics, as well as pharmacological therapies, including antidepressants, non-systemic antibiotics, serotoninreceptor modulators, chloride channel activators, guanylate cyclase $C$ receptor agonists, mixed $\mu$ - and א-opioid receptor agonist and $\delta$ antagonists, and alpha $2 \delta$ ligands. Traditional Chinese medicine, 


\section{香港成人腸易激綜合症的治療現況：共識聲明 \\ 胡志遠、陳安安、陳雅文、張智良、張鼎堅、關治邦、 梁景秋、麥敦平、施螕知、王衛民}

目的：香港腸易激綜合症的估計現患率為 $6.6 \%$ 。隨着藥物和非藥物治 療的可用性不斷增加, 香港腸易激綜合症諮詢委員會發表一套共識聲 明, 旨在為臨床醫生診斷和治療腸易激綜合症提供本地建議。

參與者：一個由七名胃腸科醫生、一名臨床心理學家、一名精神科醫 生和一名營養學專家組成的多學科專家小組一一香港腸易激綜合症諮 詢委員會一一於2017年4月20日舉行會議。

證據：審閲不同地區和國際社會發佈有關腸易激綜合症診斷和治療的 主要研究論文、曾萃分析、指引和共識聲明。

綜述過程：在會議前起草共識聲明大綱。所有共識聲明由與會者在一 致共識下議定。

結論：這次會議共產生24項共識聲明並分為以下四個部分：（1）患 者評估、（2）患者的心理困擾、（3）治療腸易激綜合症的飲食和替 代方法, 以及 (4) 支持腸易激綜合症藥理治療的證據。建議家庭醫 生擔任腸易激綜合症患者的主要護理角色。這套共識聲明旨在為家庭 醫生於診斷和治療本港腸易激綜合症患者方面提供指引。 including herbal medicine and acupuncture, which is valued by many Hong Kong Chinese people as an important form of complementary medical care, has also been investigated as a treatment for IBS.

The current standard of diagnosis and management of IBS is based principally on data from western studies; nonetheless cultural differences must be considered in local practice, including the differences in perception of symptoms, dietary trends, and treatment goals within the Hong Kong Chinese population.

For this reason, the Hong Kong Advisory Council on IBS developed a set of consensus statements offering guidance on the diagnosis and management of IBS in Hong Kong.

\section{Methods}

A multidisciplinary group of clinicians constituting the Hong Kong Advisory Council on IBS-seven gastroenterologists, one clinical psychologist, one psychiatrist, and one nutritionist-convened on 20 April 2017 in Hong Kong. An outline of consensus statements was created prior to the meeting; this was divided into four parts covering: (1) patient assessment; (2) psychological distress; (3) dietary and alternative approaches to managing IBS; and (4) evidence for pharmacological management of IBS. Published primary research articles, meta-analyses, and guidelines and consensus statements issued by different regional and international societies on the diagnosis and management of IBS were reviewed during the meeting. All consensus statements were finalised by the participants during the meeting, with $100 \%$ unanimity.

\section{Results}

\section{Patient assessment-from primary care to diagnosis}

Statement 1: The Rome IV criteria allow for an objective diagnosis of IBS. The long-term duration of symptoms required by the criteria to make a diagnosis, however, is too restrictive. Patients with a shorter duration of symptoms should also be treated for IBS.

The revised Rome IV criteria specify abdominal pain as a requirement for diagnosis of IBS, ${ }^{3}$ while the former Rome III criteria specified abdominal pain or discomfort (Table). ${ }^{4}$ Due to cultural differences and connotations of the word 'pain' in Chinese languages, Chinese patients are more likely to complain of 'bloating' and 'discomfort' than 'pain' when they were describing their symptoms. ${ }^{5}$ Patients with abdominal discomfort or bloating without pain as the dominant symptom should also be considered for diagnosis of IBS in real-life clinical practice.

Statement 2: Physicians should make a positive symptom-based clinical diagnosis; there are no confirmatory diagnostic tests for IBS. ${ }^{3}$

Physicians should exercise clinical judgement in determining appropriate investigations (eg blood tests, stool tests, diagnostic imaging), considering age, family history, and the presence of alarming symptoms. $^{6}$ Specific investigations such as colonoscopy or abdominal imaging are not routinely

TABLE. Rome III and Rome IV criteria for irritable bowel syndrome $e^{3,4}$

\begin{tabular}{|c|c|}
\hline Rome III & Rome IV \\
\hline $\begin{array}{l}\text { Recurrent abdominal pain or discomfort at least } 3 \text { days/month in the } \\
\text { last } 3 \text { months associated with two or more of the following criteria*: } \\
\text { - Improvement with defaecation } \\
\text { - Onset associated with a change in frequency of stool } \\
\text { - Onset associated with a change in form (appearance) of stool }\end{array}$ & $\begin{array}{l}\text { Recurrent abdominal pain on average at least } 1 \text { day/week in the last } \\
3 \text { months associated with two or more of the following criteria*: } \\
\text { - Related to defaecation } \\
\text { - Associated with a change in frequency of stool } \\
\text { - Associated with a change in form (appearance) of stool }\end{array}$ \\
\hline
\end{tabular}

* Criteria fulfilled for the last 3 months with symptom onset at least 6 months prior to diagnosis 
recommended in patients younger than 50 years without specific risk factors. ${ }^{7}$

Statement 3: Inflammatory bowel disease (Crohn's disease and ulcerative colitis) and colorectal cancer are the most important differential diagnoses of IBS and should be actively excluded in patients who present with IBS-related symptoms. ${ }^{6,8}$

Additional differential diagnoses include enteric infections, medications, gynaecological pathologies in female patients (eg endometriosis, uterine fibroids, pelvic inflammatory disease), pancreatic disorders, metabolic diseases (eg hypercalcaemia), and ischaemic bowel disease in elderly patients.., 9

Statement 4: Primary care providers should be the principal physicians to diagnose and manage IBS.

Compared with specialists, primary care providers have the advantage of being more familiar with a patient and are able to provide medical care with a holistic approach, which is important when managing a multifaceted disease such as IBS. ${ }^{6}$ Psychological well-being and lifestyle factors (eg exercise, diet, stress-coping strategies, sleep) should be addressed. ${ }^{6}$ Primary care providers should also educate patients about the disease, provide reassurance about prognosis, and manage expectations of treatment. ${ }^{6,10}$ Primary care providers should recognise alarming symptoms or indicators suggestive of organic pathology of the gastrointestinal tract (eg anaemia, weight loss, bleeding) or significant health problems; referral to other disciplines should be made where appropriate. ${ }^{6,11}$ It is also important to recognise the risk of (unwarranted) frequent consultations and specialist referrals that will cause unnecessary stress for the patient and prolonged anxiety regarding their health. ${ }^{10}$

Statement 5: The main treatment objectives in IBS are: symptomatic relief, improved quality of life, reduced functional impairment, education, and empowerment. ${ }^{6}$

It is important for physicians to verbally acknowledge to patients that they have a clinical condition with bothersome symptoms, while reassuring them about their fears of severe underlying conditions or deterioration of health; or to reassure patients about their prognosis in the case of post-infectious IBS. ${ }^{10}$

\section{Understanding the patient's psychological distress}

Statement 6: Anxiety and depressive disorders are mental morbidities that are commonly observed in patients with IBS and should be actively screened for and managed. Sleep disturbances may be a symptom of more severe mental distress.

In a community-based survey in Hong Kong, the prevalence of generalised anxiety disorder was
$16.5 \%$ in patients with IBS, compared with $3.3 \%$ in the general population (odds ratio $[\mathrm{OR}]=5.8$ ). ${ }^{12}$ A Taiwanese cohort of 4689 patients also found increased risks of depressive disorder (hazard ratio $[\mathrm{HR}]=2.89$; 95\% confidence interval $[\mathrm{CI}], 2.30-3.19$ ), anxiety disorder $(\mathrm{HR}=2.89$; $95 \% \mathrm{CI}, 2.42-3.46)$, and sleep disorder ( $\mathrm{HR}=2.47 ; 95 \% \mathrm{CI}, 2.02-3.02)$ in patients with IBS. ${ }^{13}$ In a cross-sectional study of 201 subjects with IBS, $67.2 \%$ were poor sleepers. ${ }^{14}$ The correlation between sleep score and IBS severity was independent of anxiety and depression; nonetheless the prevalence of sleep disturbances was higher in patients with co-morbid anxiety and depression. ${ }^{14}$

Statement 7: Mental health morbidities in patients with IBS should be screened for in the primary care setting. Patients with mental health morbidities should be encouraged to consult mental health professionals. Referral to a psychiatrist is indicated for psychosis, suicidal ideation, violent behaviour, or other life-threatening conditions. ${ }^{6}$

Hints of mental morbidities include ${ }^{14,15}$ :

- persistently low mood and/or reduced enjoyment of pleasurable activities;

multiple and extra-intestinal somatic symptoms;

stress-related gastrointestinal symptoms;

- family history of mental illness;

suicidal ideation or a history of such attempts;

sleep disturbance;

significant functional impairment; and

- health anxiety ${ }^{10}$ :

o repeated investigations

- relentless search for health information

Standardised instruments (eg Patient Health Questionnaire $[\mathrm{PHQ}]$ ) can easily be administered to facilitate clinical assessments. The PHQ is available online in Cantonese and is appropriate for use in primary care clinics. ${ }^{16}$ Mild-to-moderate anxiety and depression can be managed in the primary care setting. Physicians should routinely counsel patients on the importance of mental health in the management of IBS.

Counselling and face-to-face psychological interventions have been found to be efficacious in the management of IBS. A study of 149 patients with moderate or severe IBS resistant to the antispasmodic agent mebeverine found that the addition of cognitive behavioural therapy, delivered by primary care nurses, had a considerable initial benefit on symptom severity compared with mebeverine alone, with the benefit persisting after 3 and 5 months. ${ }^{17}$ Cognitive behavioural therapy also showed a significant benefit on the work and social adjustment scale that persisted 12 months after therapy (mean reduction of 2.8 points). ${ }^{17} \mathrm{~A}$ metaanalysis also demonstrated similar positive benefits of cognitive behavioural therapy ( $\mathrm{HR}=0.60 ; 95 \% \mathrm{CI}$, 0.44-0.83), dynamic psychotherapy ( $\mathrm{HR}=0.60 ; 95 \%$ $\mathrm{CI}, 0.39-0.93)$, hypnotherapy ( $\mathrm{HR}=0.74 ; 95 \% \mathrm{CI}$, 
0.63-0.87), and multi-component psychotherapy $(\mathrm{HR}=0.72$; 95\% CI, 0.62-0.83) compared with control treatment. $^{18}$

\section{Dietary and alternative approaches to irritable bowel syndrome}

Statement 8: A short trial of low-FODMAP diet has been shown to improve symptoms of IBS. ${ }^{19}$ Involvement of dieticians may improve accuracy and adherence to the low-FODMAP diet or other specific diets. ${ }^{20}$

In a randomised, controlled, single-blind, crossover trial, a low-FODMAP (fermentable oligosaccharides, disaccharides, monosaccharides, and polyols) diet for 21 days led to a significant improvement in symptoms of IBS (including abdominal pain, bloating, passage of gas and dissatisfaction with stool consistency) and quality of life compared with a standard Australian diet. ${ }^{19}$ Possible mechanisms include a decrease in osmotic diarrhoea, fermentation and altered gut microbiota, immune activation and visceral sensitivity. ${ }^{21,22}$

Statement 9: Other dietary concerns that may affect IBS include lactose intolerance, high-fat diet, high-fibre diet, chilli, and gluten.

These can all be potential aggravators of IBS, but do not apply to all patients. ${ }^{23}$ Coeliac disease and non-coeliac gluten sensitivity are rare in Chinese populations and therefore trial of a gluten-free diet is not warranted in Chinese patients. ${ }^{24}$

Statement 10: Health care practitioners should exercise caution in recommending excessively restrictive diets that could lead to malnutrition, quality of life impairment, or psychological distress (as a result of the difficulty of adherence).

For selected patients on long-term restrictive diets or with multiple food intolerances, referral to a dietician may help to minimise the risk of nutrient deficiency. ${ }^{20}$

Statement 11: The role of food allergy in the pathophysiology of IBS in unclear. Routine food allergy testing is not recommended. ${ }^{25}$

Statement 12: Herbal medicine has been shown to be effective only if an individualised approach is taken. This requires assessment by a Chinese medicine practitioner.

The benefit of individualised herbal medicine was shown in a 1998 study in which 116 patients with IBS were randomised to receive placebo $(n=35)$, individualised $(n=38)$, or a standard $(n=43)$ Chinese herbal medicine for 16 weeks. ${ }^{26}$ Only the individualised treatment group maintained improvement at 14 weeks after completion of treatment. ${ }^{26}$ This was confirmed by a 2006 Hong Kong study by Leung et $\mathrm{al}^{27}$ in 199 diarrhoea-predominant IBS patients randomised to receive placebo $(n=59)$ or standard $(n=60)$ Chinese herbal formula for 16 weeks. No differences in global or individual IBS symptoms or quality of life were observed at any follow-up visits.

Statement 13: The current evidence does not support acupuncture as an effective treatment for IBS.

A meta-analysis that evaluated evidence from 17 randomised controlled trials reported that acupuncture is not more effective than sham treatment for improving symptom severity $(\mathrm{P}=0.36)$ or quality of life $(\mathrm{P}=0.83) .^{28}$

\section{Pharmacological management of irritable bowel syndrome}

Statement 14: The currently approved drug classes for treatment of IBS are antispasmodics, laxatives, and antidiarrhoeal drugs.

Statement 15: There are good efficacy and safety data to support antispasmodics as first-line therapy for IBS.

A 2008 meta-analysis evaluated data from 22 randomised controlled trials comparing antispasmodics (including otilonium bromide, cimetropium, hyoscine, pinaverium, trimebutine, rociverine, alverine, dicycloverine, mebeverine, pirenzepine, prifinium, and propinox) with placebo. Of 905 patients assigned to antispasmodics, 350 (39\%) had persistent symptoms after treatment compared with 485 (56\%) of 873 allocated to placebo (relative risk $[\mathrm{RR}]=0.68 ; 95 \% \mathrm{CI}, 0.57-0.81 ; \mathrm{P}<0.001) .^{29}$ Otilonium bromide $(\mathrm{RR}=0.55 ; 95 \% \mathrm{CI}, 0.31-0.97)$ and hyoscine $(R R=0.63 ; 95 \% C I, 0.51-0.78)$ were the only antispasmodics to show consistent evidence of efficacy. The most frequent adverse events were dry mouth, dizziness and blurred vision, but none of the trials reported any serious adverse events. ${ }^{29}$

It is important to recognise that not all antispasmodics share the same efficacy and safety profile. Moreover, there are additional safety concerns (eg blurred vision, mental confusion, aggravation of prostatism, tachycardia) with antispasmodics of the anticholinergic subclass; additional monitoring is required with such agents. ${ }^{30}$

Statement 16: There is a lack of head-to-head studies comparing the efficacy and safety of different antispasmodics. Moreover, antispasmodics have varying mechanisms of action.

Hyoscine is an antispasmodic that blocks the action of muscarinic and nicotinic acetylcholine receptors in smooth muscle and secretory glands causing decreased motility of the gastrointestinal tract. ${ }^{31}$

Otilonium bromide is an antispasmodic with several modes of action that are not shared by other antispasmodics. It works by blocking L-type calcium channels on smooth muscle cells thereby restoring physiological motility. It also exhibits an antisecretory effect and reduces spasm through inhibition of muscarinic $\mathrm{M}_{3}$ receptor-coupled calcium signals. 
Finally, otilonium bromide antagonises tachykinin receptors on the intestinal smooth muscle cells and afferent nervous terminations, thus modulating the development of intestinal hyperalgesia and reducing visceral hypersensitivity by enhancing sensory thresholds to rectosigmoid distension. ${ }^{32}$

Statement 17: Otilonium bromide can be prescribed by primary care physicians as first-line therapy for IBS.

Data from a total of 883 patients with IBS from three randomised controlled trials were included in a pooled analysis. A significant therapeutic effect of otilonium bromide was observed after 10 and 15 weeks of treatment compared with placebo, with reference to intensity and frequency of abdominal pain, severity of bloating, and rate of responders as evaluated by patients and physicians. ${ }^{33}$ The most common treatment-emergent adverse events associated with otilonium bromide were gastrointestinal events (abdominal pain, flatulence, worsening IBS) and infections. Nearly all were mild to moderate $(99 \%$ in the otilonium bromide group and $98 \%$ in the placebo group) and were considered unrelated to the study treatment $(92 \%$ in the otilonium bromide group and $94 \%$ in the placebo group)..$^{34}$

Statement 18: Further study is warranted to establish an optimal treatment period for otilonium bromide.

Many patients use otilonium bromide on an as-needed basis or as prophylaxis prior to known triggering events (eg travel, large meals). Others use otilonium bromide on a long-term basis (eg those with frequent daily symptoms). A randomised, double-blind clinical trial demonstrated a lower rate of symptom relapse $(\mathrm{P}=0.009)$ and higher relapse-free probability $(\mathrm{P}=0.038)$ in patients treated with otilonium bromide for 15 weeks compared with patients treated with placebo. ${ }^{34}$ A 2-year study demonstrated a significant improvement in abdominal pain, abdominal distension, and bowel movements in patients treated with otilonium bromide, compared with a high-roughage diet. ${ }^{35}$

Statement 19: Antispasmodics are also commonly prescribed in combination with antidiarrhoeal drugs or laxatives. No clinical data, however, are available on combination therapy.

Statement 20: Selective serotonin reuptake inhibitors (SSRIs) are used in patients with comorbid anxiety or depressive disorder or as offlabel treatment for patients who do not respond to first-line treatment for IBS. Treatment with SSRIs requires close monitoring for efficacy and safety.

Selective serotonin reuptake inhibitors have proven efficacy for IBS, anxiety and depressive disorders, and should be considered when organbased treatment and psychological treatment are not accessible or effective. A meta-analysis of five randomised controlled trials found that SSRIs were more effective and better tolerated than placebo as treatment for IBS $(\mathrm{RR}=0.62$; 95\% CI, 0.450.87). ${ }^{36}$ Nonetheless, SSRIs should be prescribed by physicians or mental health professionals with experience and training in antidepressant drug treatment. Potential adverse events, including suicidal ideation in non-suicidal patients, warrants careful attention to patients taking antidepressants. ${ }^{37}$

Statement 21: Probiotics have demonstrated positive results in the treatment of IBS.

A 2013 meta-analysis found that probiotics consisting of Lactobacillus, Bifidobacterium, Escherichia, Streptococcus or combination probiotics had beneficial effects on the persistence of IBS symptoms ( $R R=0.79 ; 95 \% \mathrm{CI}, 0.70-0.89)$, global IBS, abdominal pain, bloating and flatulence scores, and led to an increase in the number of stools per week..$^{38}$ The exact mechanism of action, optimal regimen and delivery mode, and durability of efficacy remains to be determined. Moreover, although adverse events with probiotics are rare, there are little long-term safety data available. ${ }^{38}$ Finally, the efficacy of different probiotic strains is variable and limits their use as a first-line treatment. ${ }^{38}$

Statement 22: Short-term rifaximin has been found to be effective in relieving bloating symptoms.

Rifaximin is a poorly absorbed, luminally active antibiotic. A meta-analysis of five studies found that short-term use of rifaximin was effective in relieving bloating symptoms $(\mathrm{OR}=1.55$; 95\% CI, 1.23-1.96) and led to global IBS symptom improvement $(\mathrm{OR}=1.57 ; 95 \% \mathrm{CI}, 1.22-2.01) .{ }^{39}$ The role of rifaximin has not been fully acknowledged in the management algorithm of IBS owing to the concern of antibiotic resistance, risk of Clostridium difficile infection, and long-term effectiveness.

Statement 23: Other novel therapies that are Food and Drug Administration-approved based on positive results in patients with IBS, but are not yet available in the primary care setting in Hong Kong include: serotonin receptor modulators, secretagogues, and peripherally acting opioid receptor modulators.

Statement 24: There are insufficient efficacy and safety data to justify the clinical use of faecal microbiota transplantation in the management of IBS.

\section{Conclusions}

Irritable bowel syndrome is a common disorder encountered in general practice, yet effective treatment remains a challenge for primary care physicians and gastroenterologists. This is the first consensus statement on the appropriate approach to diagnosis and management of IBS in Hong Kong. This paper summarises important considerations 
in managing patients with IBS, along with clinical efficacy and safety data on pharmacological treatments. These consensus statements aimed to provide local general practitioners with information to counsel and manage patients with IBS in Hong Kong.

The treatment of IBS depends on patient symptoms. ${ }^{6}$ After actively excluding relevant and serious pathologies, psychological and dietary aspects of IBS should first be addressed. ${ }^{6}$

Food allergy testing is not recommended in patients with $\mathrm{IBS}^{25}$; nonetheless important dietary considerations include FODMAPs, fibre, chilli, lactose, and gluten. ${ }^{23}$ Coeliac disease is rare in the Chinese population; data suggest that wheat is not completely absorbed in the small bowel and may produce gastrointestinal symptoms. ${ }^{23}$ Although the primary carbohydrate in the Chinese diet is rice, there is a strong influence of western cuisine in Hong Kong and wheat is found in many traditional Hong Kong-style foods.

Anxiety and depression are common in patients with IBS. Psychological interventions such as counselling, cognitive behavioural therapy, and hypnotherapy are effective treatments for patients with mental morbidities and IBS. ${ }^{17,18}$ Physicians should routinely counsel patients on the importance of mental health in the management of IBS.

Motivated patients may consider traditional Chinese medicine but an individualised approach must be taken. ${ }^{26}$ At this time, there is insufficient evidence to recommend acupuncture for patients with IBS. ${ }^{28}$

The currently approved drug classes for treatment of IBS are antispasmodics, laxatives, and antidiarrhoeal drugs. Antispasmodics are a heterogeneous drug class with varying mechanisms of action. Otilonium bromide and hyoscine are the only antispasmodics to show consistent evidence of efficacy but the anticholinergic side-effect of hyoscine has limited its frequent use in IBS. ${ }^{29,31}$

\section{Acknowledgements}

English language editing and writing support, funded by an unrestricted educational grant from A. Menarini Hong Kong Limited, was provided by Cassandra Thomson of MIMS (Hong Kong) Limited.

\section{Declaration}

All authors have disclosed no conflicts of interest.

\section{References}

1. Kwan AC, Hu WH, Chan YK, Yeung YW, Lai TS, Yuen H. Prevalence of irritable bowel syndrome in Hong Kong. J Gastroenterol Hepatol 2002;17:1180-6.

2. Camilleri M. Peripheral mechanisms in irritable bowe syndrome. N Engl J Med 2012;367:1626-35.
3. Lacy BE, Mearin F, Chang L, et al. Bowel disorders. Gastroenterology 2016 Feb 18. Epub ahead of print.

4. Shih DQ, Kwan LY. All roads lead to Rome: update on Rome III criteria and new treatment options. Gastroenterol Rep 2007;1:56-65.

5. Gwee KA, Lu CL, Ghoshal UC. Epidemiology of irritable bowel syndrome in Asia: something old, something new, something borrowed. J Gastroenterol Hepatol 2009;24:1601-7.

6. Khanbhai A, Singh Sura D. Irritable bowel syndrome for primary care physicians. Br J Med Pract 2013;6:a608.

7. Hong Kong Department of Health. About colorectal cancer 2016. Available from: http://www.colonscreen.gov. hk/en/public/about_crc/who_should_be_screened_and_ who_need_not_be_screened.html. Accessed 1 Jun 2017.

8. Zammit E. The irritable bowel syndrome. Malta Med J 2009;21:34-40.

9. Cartwright SL, Knudson MP. Evaluation of acute abdominal pain in adults. Am Fam Physician 2008;77:971-8.

10. O'Sullivan MA, Mahmud N, Kelleher DP, Lovett E, O'Morain CA. Patient knowledge and educational needs in irritable bowel syndrome. Eur J Gastroenterol Hepatol 2000;12:39-43.

11. Hookway C, Buckner S, Crosland P, Longson D. Irritable bowel syndrome in adults in primary care: summary of updated NICE guidance. BMJ 2015;350:h701.

12. Lee S, Wu J, Ma YL, Tsang A, Guo WJ, Sung J. Irritable bowel syndrome is strongly associated with generalized anxiety disorder: a community study. Aliment Pharmacol Ther 2009;30:643-51.

13. Lee YT, Hu LY, Shen CC, et al. Risk of psychiatric disorders following irritable bowel syndrome: a nationwide populationbased cohort study. PLoS One 2015;10:e0133283.

14. Moradian-Shahrbabaki M, Vahedi H, SadeghniiatHaghighi K, Shamsipour M. Tracing the relationships between sleep disturbances and symptoms of irritable bowel syndrome. J Sleep Sci 2016;1:101-8.

15. Fadgyas-Stanculete M, Buga AM, Popa-Wagner A, Dumitrascu DL. The relationship between irritable bowel syndrome and psychiatric disorders: from molecular changes to clinical manifestations. J Mol Psychiatry 2014;2:4.

16. Yu X, Stewart SM, Wong PT, Lam TH. Screening for depression with the Patient Health Questionnaire-2 (PHQ-2) among the general population in Hong Kong. J Affect Disord 2011;134:444-7.

17. Kennedy T, Jones R, Darnley S, Seed P, Wessely S, Chalder T. Cognitive behaviour therapy in addition to antispasmodic treatment for irritable bowel syndrome in primary care: randomised controlled trial. BMJ 2005;331:435.

18. FordAC, QuigleyEM,LacyBE, etal.Effect of antidepressants and psychological therapies, including hypnotherapy, in irritable bowel syndrome: systematic review and metaanalysis. Am J Gastroenterol 2014;109:1350-65.

19. Halmos EP, Power VA, Shepherd SJ, Gibson PR, Muir JG. A diet low in FODMAPs reduces symptoms of irritable bowel syndrome. Gastroenterology 2014;146:67-75.e5.

20. Nanayakkara WS, Skidmore PM, O’Brien L, Wilkinson TJ, Gearry RB. Efficacy of the low FODMAP diet for treating irritable bowel syndrome: the evidence to date. Clin Exp Gastroenterol 2016;9:131-42.

21. Hayes PA, Fraher MH, Quigley EM. Irritable bowel syndrome: the role of food in pathogenesis and management. 
Gastroenterol Hepatol (N Y) 2014;10:164-74.

22. De Palma G, Reed DE, Pigrau M, et al. Diet-microbiota interactions underlie symptoms' generation in IBS. Gastroenterology 2017;152(5 Suppl 1):S160.

23. Gonlachanvit S. Are rice and spicy diet good for functional gastrointestinal disorders? J Neurogastroenterol Motil 2010;16:131-8.

24. Jiang LL, Zhang BL, Liu YS. Is adult celiac disease really uncommon in Chinese? J Zhejiang Univ Sci B 2009;10:16871.

25. Kennedy DA, Lewis E, Cooley K, Fritz H. An exploratory comparative investigation of Food Allergy/Sensitivity Testing in IBS (the FAST study): a comparison between various laboratory methods and an elimination diet. Adv Integr Med 2014;1:124-30.

26. Bensoussan A, Talley NJ, Hing M, Menzies R, Guo A, Ngu $M$. Treatment of irritable bowel syndrome with Chinese herbal medicine: a randomized controlled trial. JAMA 1998;280:1585-9.

27. Leung WK, Wu JC, Liang SM, et al. Treatment of diarrheapredominant irritable bowel syndrome with traditional Chinese herbal medicine: a randomized placebo-controlled trial. Am J Gastroenterol 2006;101:1574-80.

28. Manheimer E, Wieland LS, Cheng K, et al. Acupuncture for irritable bowel syndrome: systematic review and metaanalysis. Am J Gastroenterol 2012;107:835-47.

29. Ford AC, Talley NJ, Spiegel BM, et al. Effect of fibre, antispasmodics, and peppermint oil in the treatment of irritable bowel syndrome: systematic review and metaanalysis. BMJ 2008;337:a2313.

30. Hesch K. Agents for treatment of overactive bladder: a therapeutic class review. Proc (Bayl Univ Med Cent) 2007;20:307-14.

31. Samuels LA. Pharmacotherapy update: hyoscine butylbromide in the treatment of abdominal spasms. Clin Med Ther 2009;1:647-55.

32. Triantafillidis JK, Malgarinos G. Long-term efficacy and safety of otilonium bromide in the management of irritable bowel syndrome: a literature review. Clin Exp Gastroenterol 2014;7:75-82.

33. Clavé P, Tack J. Efficacy of otilonium bromide in irritable bowel syndrome: a pooled analysis. Therap Adv Gastroenterol 2017;10:311-22.

34. Clavé P, Acalovschi M, Triantafillidis JK, et al. Randomised clinical trial: otilonium bromide improves frequency of abdominal pain, severity of distention and time to relapse in patients with irritable bowel syndrome. Aliment Pharmacol Ther 2011;34:432-42.

35. Villagrasa M, Boix J, Humbert P, Quer JC. Aleatory clinical study comparing otilonium bromide with a fiber-rich diet in the treatment of irritable bowel syndrome. Ital J Gastroenterol 1991;23(8 Suppl 1):67-70.

36. Ford AC, Talley NJ, Schoenfeld PS, Quigley EM, Moayyedi P. Efficacy of antidepressants and psychological therapies in irritable bowel syndrome: systematic review and metaanalysis. Gut 2009;58:367-78.

37. Bielefeldt AØ, Danborg PB, Gøtzsche PC. Precursors to suicidality and violence on antidepressants: systematic review of trials in adult healthy volunteers. J R Soc Med 2016;109:381-92.

38. Ford AC, Quigley EM, Lacy BE, et al. Efficacy of prebiotics, probiotics, and synbiotics in irritable bowel syndrome and chronic idiopathic constipation: systematic review and meta-analysis. Am J Gastroenterol 2014;109:1547-61.

39. Menees SB, Maneerattannaporn M, Kim HM, Chey WD. The efficacy and safety of rifaximin for the irritable bowel syndrome: a systematic review and meta-analysis. Am J Gastroenterol 2012;107:28-35. 